\title{
Refining of Rough Indium by Method of Reactionary Electrolysis
}

Bibisara Burkitbayeva, Akmaral Argimbayeva, Gulmira Rakhymbay ${ }^{*}$, Khaisa Avchukir, Khaidar Tassibekov, and Mikhail Nauryzbayev

Al-Farabi Kazakh National University, Center of Physico-Chemical Methods of Research and Analysis, Almaty, Kazakhstan

\begin{abstract}
Electro-refining of rough indium by method of reactionary electrolysis from the chloride solutions containing $\mathrm{InCl}_{3}$ was carried out. The research of ionization of rough and modified indium anodes showed a decrease in an overvoltage of dissolution of indium when using the anodes containing bismuth. The values of the activation energy of the ionization stage of rough to $7.3 \mathrm{~kJ} /$ mole and the indium anodes modified by bismuth with 5- and 10-fold excess of depressor in relation to the total content of impurities, amounted to 5.6 and $3.7 \mathrm{~kJ} /$ mole, respectively. Results of the analysis of the refined indium by ICP-OES and ICP-MS methods showed that use of bismuth as a depressor additive allowed reducing impurity $(\mathrm{Zn}, \mathrm{Pb}, \mathrm{Cd}, \mathrm{Cu}, \mathrm{Fe}, \mathrm{Ni}, \mathrm{As}, \mathrm{Tl})$ level to $1.1 \mathrm{ppm}$.
\end{abstract}

\section{Introduction}

Indium is a rare and trace elements, with a number of unique properties. For use in a variety of industries: production of screens LCD monitors, TVs, and LED, fiber optics and electronics indium of high purity with a total impurity content of $10-0.01 \mathrm{ppm}$ is required [1].

In the works [2-4] devoted to refining of indium in various electrolytes on solid electrodes the multistage techniques including chemical refining, vacuum still and electro-refining are presented. When using of the combined methods from chloride and sulphate electrolytes optimum conditions of purification of indium were established and metal of brand $6 \mathrm{~N}$ [5] is received.

The authors of papers [6,7] developed a highly effective method of reactionary electrolysis with electrolyte pre-refining. This method is based on the principle of binding the impurities, contained in the purified metal in electrochemically inactive compounds by antimony additives.

In this paper, for purification of rough indium the method of reactionary electrolysis was used, with high productivity, the ability to process automation, ease of hardware design and the lack of multi-stage. This method allows reducing the total impurity content in the reduced indium.

Research objective is to receive the cathode precipitations of indium of high purity with minimum energy consumption, using the method of electrolysis reaction, in which bismuth is used as the depressor additive for the first time. In comparison with antimony, bismuth forms the stronger electrochemical inactive inter-metallides with the difficult deleted impurity metals.

\section{Experimental part}

Preparation of the modified anodes was carried out in the cylindrical heat-resistant reactor made of quartz and included two stages: preparation of a fusible alloy (ligature) of $\mathrm{In}+\mathrm{In}_{2} \mathrm{Bi}$ and receiving anodes with various content of bismuth.

The ligature of a bismuth was prepared by an alloy of indium of the In-2 brand (78\%) with a bismuth (purity of $99.999 \%$, Sigma Aldrich) $(22 \%)$ at $270^{\circ} \mathrm{C}$ under a paraffin layer when hashing within one hour which was used further for manufacture of the modified anodes of indium.

Rough indium of the IN-2 brand contains 0.01 wt. \% of the impurity metals. Two modified anodes were prepared: A2 - with 5-fold, A3 - with 10-fold excess of bismuth in relation to the total content of metalsimpurity. Proceeding from the calculated necessary content of bismuth, the quantity of a ligature was defined and alloyed with rough indium at a temperature of $250^{\circ} \mathrm{C}$ under a paraffin layer within one hour with continuously mixing a melt.

Electro-oxidation of indium is investigated by method of the linear voltammetry in a temperaturecontrolled three-electrode cell with a capacity of $50 \mathrm{ml}$, with use of a potentsiostat-galvanostat of Autolab PGSTAT $302 \mathrm{~N}$. The working electrodes were rough (A1) and the indium electrodes modified by bismuth (A2, A3) with an area of $0.196 \mathrm{~cm}^{2}$. The auxiliary electrode was a platinum plate with an area of $12.96 \mathrm{~cm}^{2}$, silver chloride electrode served as the reference electrode.

All experiments were made at a temperature of $25^{\circ} \mathrm{C}$, with an accuracy of \pm 0.1 . Polarization resistance measurements were carried out at $-10 \mathrm{mV}$ to $+10 \mathrm{mV}$ vs.

Corresponding author: gulmirarahymbay@,gmail.com 
$\mathrm{E}_{\mathrm{OCP}}$ at scan rate of $5 \mathrm{mV} / \mathrm{s}$. Polarization curves recorded again with a scan rate of $5 \mathrm{mV} / \mathrm{s}$ in the range of -300 $\mathrm{mV}$ to $+300 \mathrm{mV}$ vs. $\mathrm{E}_{\mathrm{OCP}}$.

Chloride solution containing $0.5 \mathrm{M} \mathrm{InCl}_{3}+2.0 \mathrm{M}$ $\mathrm{NaCl}(\mathrm{pH}=1.5)$ was used as the electrolyte during the electrochemical study of oxidation of indium and electrolysis. Supporting electrolyte prepared from sodium chloride received by a triple recrystallization of chemically pure salt $(99.9 \%)$. The $\mathrm{pH} 1.5$ of solution was created by acidification with hydrochloric acid.

Use of chloride electrolytes with the content of indium salt of $0.5 \mathrm{~mole} / 1$ allowed obtaining qualitative precipitates of indium with a large current output. The choice of 2.0 M solution of sodium chloride as a blank electrolyte is caused by its high conductivity and optimum viscosity. As it follows from work [4] the variation of concentration of Sodium chloride does not influence on the size of a current output, however an increase in its contents considerably reduces a voltage drop in an electrolysis bath.

Electrochemical cell for the electrolysis consisted of anode (A1, A2 or A3) and titanium cathode (BT1-0) with an area of $1 \mathrm{~cm}^{2}$. Preparation of the anode and the cathode surfaces was carried out mechanically using the micron cloth and rinsing with bidistilled water before each measurement. To assess the reproducibility, each measurement was performed at least three times. Refining of indium using rough and modified anodes was performed in the galvanostatic mode at room temperature at a current density of $300 \mathrm{~A} / \mathrm{m}^{2}$. Effective inter-electrode distance was $2.0 \mathrm{~cm}$. After electrolysis the cathode precipitate thoroughly was washed with redistilled water, and dried in a desiccator for a day.

Samples were prepared by dissolving $0.1 \mathrm{~g}$ of indium precipitated in $2.5 \mathrm{ml}$ of nitric acid (OFS) and bringing to the mark with double-distilled water in a volumetric flask of $25 \mathrm{ml}$. The composition of the samples of refined indium was determined by optical emission spectrometry (ICP-OES) and mass spectrometry (ICPMS) with inductively coupled plasma on Optima 8000
(Perkin Elmer Company) and ICP-MS Agilent-75a, respectively.

\section{Results and discussion}

\subsection{Anodic dissolution of rough and modified indium anodes.}

One of stages of electrochemical refining of metal is its oxidation. In $[8,9]$ oxidation of indium in sulphate and chloride electrolytes at various temperatures to determine the optimal conditions for the electrochemical refining of rough indium was investigated. The anodic dissolution of indium in chloride electrolytes proceeds with a lower overvoltage, than in the perchlorate and sulphate, that is explained by an activating effect of chloride ions and the higher stability of chloride complexes of indium.

In this work the anode behavior of rough and the modified indium anodes containing 5 and 10-fold excess of bismuth relative to the content of metal impurities is studied. Insufficient bismuth content in the anode may result in its preferential interaction with indium and incomplete binding of impurities, especially at their small contents. Excessive bismuth content can lead to contamination by bismuth of cathode precipitates. The use of bismuth is due to the formation of strong bonds $\mathrm{Bi}-\mathrm{Tl}$ and $\mathrm{Bi}-\mathrm{Zn}$, which is evident from a comparison of the values of change of the Gibbs free energy of formation of bonds $\mathrm{Bi}-\mathrm{Tl}, \mathrm{Bi}-\mathrm{Zn}$ and $\mathrm{In}-\mathrm{Bi}$.

Selection of a ligatures composition according to the phase diagram of the In-Bi system, is caused by its low melting point $\left(72^{\circ} \mathrm{C}\right)$ and high indium content that improves the distribution of the inter-metallide $\operatorname{In}_{2} \mathrm{Bi}$ in the volume of melt [10].

Electrochemical disolution of indium anodes is investigated by the potentio-dynamic method which allowed to determine kinetic parameters of process (Fig. $1)$.

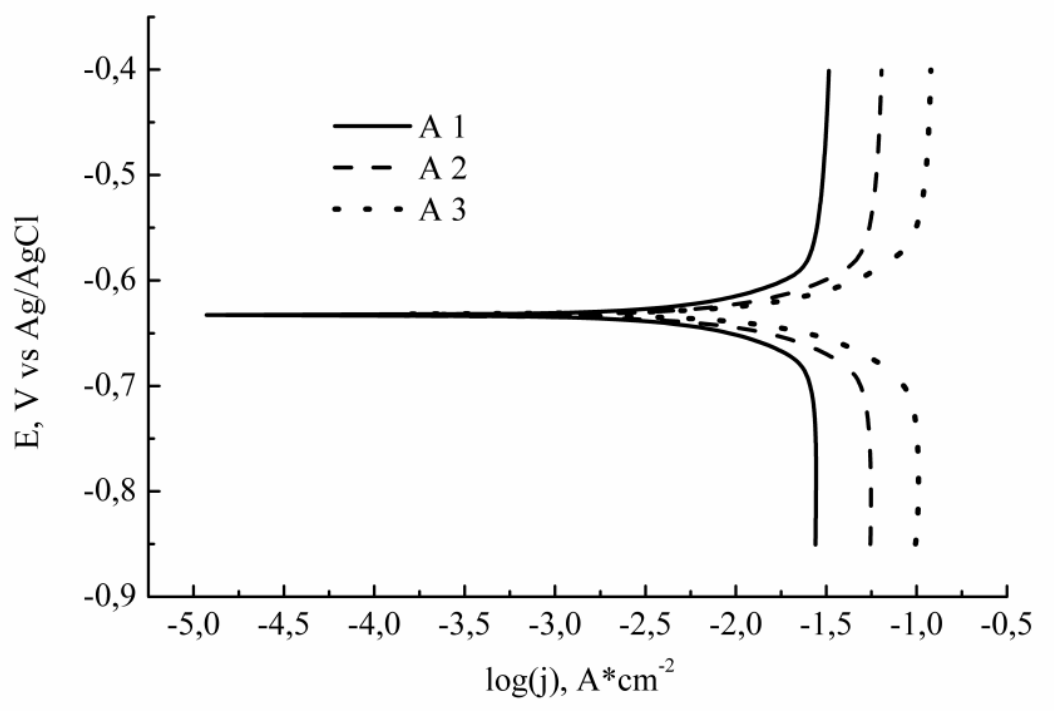

Fig. 1. Cathodic and anodic polarization curves for various anodes in the solution of $0.5 \mathrm{M} \mathrm{InCl}_{3}+2.0 \mathrm{M} \mathrm{NaCl}, v=5 \mathrm{mV} / \mathrm{s}, \mathrm{T}=25$ ${ }^{\circ} \mathrm{C}$ : A1 - rough indium, A2 - modified indium with 5 fold, A3 - 10 fold excess of Bi relative to the total content of metal impurities. 
As seen in Figure 1, an increase in the content of a depressant in the anode leads to the growth of indium ionization current without changing the equilibrium potential. From polarization curves the polarization resistance, exchange current and Tafel's constant $b_{a}$, which according to the Battler-Folmer equation is directly proportional to a charge transport coefficient (1a) (Table 1), were calculated.

Table 1. onization parameters of rough and modified indium anodes.

\begin{tabular}{|c|c|c|c|}
\hline Anode & $\mathbf{j}_{\mathbf{o}}, \mathbf{m A} / \mathbf{c m}^{\mathbf{2}}$ & $\mathbf{b}_{\mathbf{a}}, \mathbf{m V} / \mathbf{d e c}$ & $\mathbf{R}_{\mathbf{p}}, \mathbf{\Omega}^{*} \mathbf{c m}^{\mathbf{2}}$ \\
\hline A1 & 19.98 & 189 & 1.84 \\
\hline A2 & 67.86 & 231 & 1.11 \\
\hline A3 & 103.24 & 293 & 0.72 \\
\hline
\end{tabular}

Note: A1 - rough indium, A2 - modified indium with 5-fold, A3 - 10-fold excess of bismuth (relative to the total content of metal impurities).
With an increase in the content of bismuth in the anode a decrease in the polarization resistance occurs. This leads to an increase in the exchange current. This apparently is due to the activating effect of depressor additives that cause a decrease of the energy barrier of electron transfer, which is characterized by the coefficient of electron transfer proportional to $b_{a}$. The values of the activation energy of process of ionization of rough (A1) and modified (A2, A3) of indium anodes, received from the analysis of the dependence of values of the logarithm of their exchange currents on temperature (Fig 2.), were 7.3; 5.6 and $3.7 \mathrm{~kJ} / \mathrm{mole}$, respectively.

Values of activation energy testify to the diffusion nature of process of ionization. The obtained data indicate a decrease in an overvoltage (over-potential) during the oxidation of indium in the modified electrodes in the following row: $\eta_{(\mathrm{A} 1)}>\eta_{(\mathrm{A} 2)}>\eta_{(\mathrm{A} 3)}$.

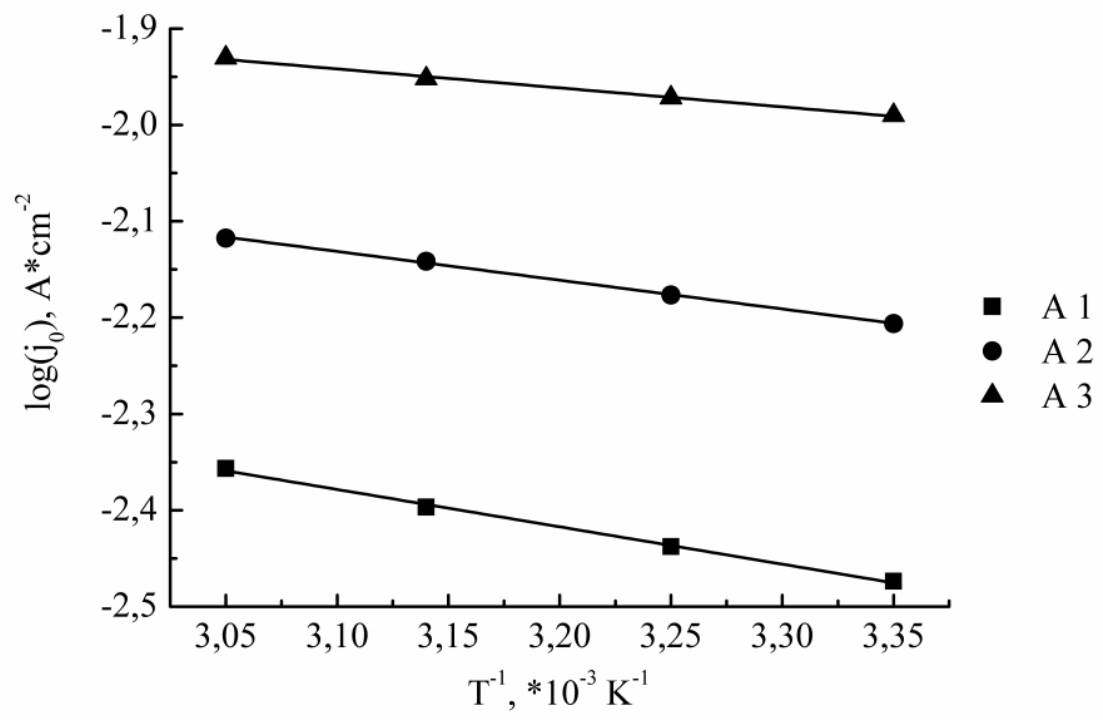

Fig. 2. Dependence of the exchange current density logarithm from inverse temperature values for different anodes in the solution of $0.5 \mathrm{M} \mathrm{InCl}_{3}+2.0 \mathrm{M} \mathrm{NaCl}, v=0.05 \mathrm{~V} / \mathrm{s}$ : $\mathrm{A} 1-$ rough indium, $\mathrm{A} 2-$ modified indium with 5 fold, $\mathrm{A} 3-10$ fold excess of $\mathrm{Bi}$ relative to the total content of metal impurities.

\subsection{Electro-refining of indium}

The character of the electrode processes during the electrolysis depends on many factors: the electrode material, the composition of electrolyte, electrolysis mode (current density, temperature and inter-electrode distance). Electrolysis was carried out with rough and modified indium anodes with different content of bismuth.

From the measured values of voltage on the electrolytic cell, the specific energy consumption has been calculated for $1 \mathrm{t}$ of cathode precipitates (Table 2).

The received results showed that modifying of the anode by bismuth at electrochemical refining of indium contributes to maintaining of high yield of indium on current, the voltage drop in the electrolytic cell and consequently a decrease in specific energy consumption.
Table 2. Energy characteristics of electrolytic refining of rough and modified indium anodes.

\begin{tabular}{|c|c|c|c|}
\hline Anode & $\begin{array}{c}\text { Voltage } \\
\text { (U), V }\end{array}$ & $\begin{array}{c}\text { Current } \\
\text { efficiency, \% }\end{array}$ & $\begin{array}{l}\text { Specific energy } \\
\text { consumption } \\
\text { (SEC), kW'ht } \mathbf{t}^{-1}\end{array}$ \\
\hline A1 & 0.62 & 99.3 & 430 \\
\hline $\mathrm{A} 2$ & 0.52 & 98.3 & 371 \\
\hline A3 & 0.55 & 99.9 & 386 \\
\hline
\end{tabular}

Note: A1 - rough indium, A2 - modified indium with 5-fold, A3 - 10-fold excess of bismuth (relative to the total content of metal impurities). 
Table 3. Results of ICP-OES analysis of the composition of rough indium and cathode precipitates of indium.

\begin{tabular}{|c|c|c|c|c|}
\hline \multirow{2}{*}{$\mathbf{M e}$} & $\begin{array}{c}\text { Composition } \\
\text { of rough } \\
\text { indium, } \\
\text { wt.*10 }\end{array}$ & \multicolumn{3}{|c|}{$\begin{array}{c}\text { Composition of cathode } \\
\text { precipitates, wt.*10 }\end{array}$} \\
\cline { 3 - 5 } & $\mathbf{A 1}$ & $\mathbf{A 2}$ & $\mathbf{A 3}$ \\
\hline $\mathrm{Cd}$ & 1.00 & 3.23 & 0.62 & 1.77 \\
\hline $\mathrm{Cu}$ & 1.00 & 7.69 & - & - \\
\hline $\mathrm{Fe}$ & 1.00 & - & - & - \\
\hline $\mathrm{Ni}$ & 0.50 & 4.05 & 0.91 & 0.70 \\
\hline $\mathrm{Pb}$ & 1.00 & 83.50 & 0.65 & 0.97 \\
\hline $\mathrm{Sn}$ & 1.00 & - & 1.63 & - \\
\hline $\mathrm{Tl}$ & 1.00 & 70.50 & 1.67 & 6.05 \\
\hline $\mathrm{Zn}$ & 3.00 & 2.91 & 2.19 & 0.19 \\
\hline $\mathrm{In}$ & 99.99050 & 99.99825 & 99.99989 & 99.99940 \\
\hline
\end{tabular}

Note: A1 - rough indium, A2 - modified indium with 5 fold, A3 - 10 fold excess of Bi relative to the total content of metal impurities.

Table 4. Results of ICP-MS analysis of the composition of rough indium and indium cathode precipitates.

\begin{tabular}{|c|c|c|c|c|}
\hline \multirow{2}{*}{$\mathbf{M e}$} & \multirow{2}{*}{$\begin{array}{c}\text { Composition } \\
\text { of rough } \\
\text { indium, } \\
\text { wt.*10 }\end{array}$} & \multicolumn{3}{|c|}{$\begin{array}{c}\text { Composition of cathode } \\
\text { precipitates, wt.*10-5 \% }\end{array}$} \\
\cline { 4 - 6 } & $\mathbf{A 1}$ & $\mathbf{A 2}$ & $\mathbf{A 3}$ \\
\hline $\mathrm{Cd}$ & 1.00 & 1.7 & 1.4 & 1.77 \\
\hline $\mathrm{Cu}$ & 1.00 & 5.13 & 3.72 & 6.05 \\
\hline $\mathrm{Fe}$ & 1.00 & - & - & - \\
\hline $\mathrm{Ni}$ & 0.50 & 3.95 & - & 2.52 \\
\hline $\mathrm{Pb}$ & 1.00 & 87.5 & - & 32.8 \\
\hline $\mathrm{As}$ & 1.00 & - & 1.63 & - \\
\hline $\mathrm{Tl}$ & 1.00 & 69.5 & 1.67 & 6.05 \\
\hline $\mathrm{Zn}$ & 3.00 & - & 0.93 & - \\
\hline $\mathrm{In}$ & 99.99050 & 99.99832 & 99.99990 & 99.99951 \\
\hline
\end{tabular}

Note: A1 - rough indium, A2 - modified indium with 5 fold, A3 - 10 fold excess of $\mathrm{Bi}$ relative to the total content of metal impurities.

Studying of anodic dissolution of indium anodes showed a decrease of values of activation energy and polarization resistance in case of use of depressor additive. This is a proof of decrease in energy costs at refining of the modified rough indium.

The results of ICP -OES and ICP- MS analysis of cathode precipitates of indium at the refining of rough and modified indium anodes are presented in Table 3 and Table 4.

As appears from the above-presented results (Table 3 and Table 4) the content of the main metal, after cleaning of the anode of rough indium, made $99.998 \%$ that means an increase in purity of indium. In case of refining of the anode modified with 5-fold excess of bismuth, purity of cathode precipitates considerably increases $(99.99989 \%)$, that is the basis of possible use of bismuth as depressor additive.

\section{Conclusion}

The indium refinement by a reactionary electrolysis in the presence of a bismuth as the promoting additive which allowed reducing activation energy of a stage of ionization of indium from $7.3 \mathrm{~kJ} /$ mole for the anode from rough metal to $3.7 \mathrm{~kJ} /$ mole - for the modified electrode was carried out. Bismuth additive in anode material leads to a voltage drop in an electrolytic bath on $100 \mathrm{mV}$ and to decrease of energy consumption.

Results of the analysis of the refined indium demonstrate increase in purity of metal by 90 times.

\section{References}

1. A.G. Morachevskii, Rus. Appl. Chem. 79(3), 516 (2006)

2. L.A. Kazanbaev, P.A. Kozlov, V.L. Kubasov, Indium Production technology (Ore and Metals, Moscow, 2004)

3. M.S. Lee, K.Y. Sohn, J. Mater. Sci. 38(24), 4843 (2003)

4. J. C. Park, Bull. Korean Chem. Soc. 32(10) 3796 (2011)

5. Z.-H. Zhou, J.-M. Ruan, H.-B. Mo, J. Mater. Sci. 40, 6529 (2005)

6. L.F. Kozin, S.N. Nagibin, E.I. Chabanenko, HighClean Substances (Vysokochistye veshestva) 5, 30 (1996)

7. L.F. Kozin, S.N. Nagibin, E.I. Chabanenko, A.C. SU 1802533 A1. USSR. 02.01.91.

8. G.S. Rakhymbay, M.K. Nauryzbayev, B.D. Burkitbayeva, A.M. Argimbaeva, A.P. Kurbatov, F. Vacandio, Eurasian Chem.-Technol. J., 16, 5 (2014)

9. B.D. Burkitbayeva, A.M. Argimbaeva, G.S. Rakhymbay, Kh. Avchukir, G.S. Beisenova, F. Vacandio, D. Tukhmetova, Chem. Bulletin of KazNU, 1, 7 (2016)

10. S.P. Yatsenko, Indium Properties and Applications, (Nauka, Moscow, 1987) 